\title{
O UNIVERSO DOS CONTOS GAUCHESCOS *
}

\section{Marllene Welnhardt}

O presento trabalho se propõe estudar o efeito das constantes verificadas em minucioso levantamento da obra em questão. Como se poderá constatar no desenvolvimento, deu-se atenção àqueles traços que reaparecem insistentemente, configurando um universo. As diversas narrativas que constituem o livro de contos foram analisadas visando levantar os aspectos comuns que. disfarçados sob uma ou outra intriga, constituem uma obsessão do narrador.

Contar é viver. 1 Narrativa e vida representam a mesma coisa. A ausência da narrativa é igual à morte. Blau conta; Blau vive. Ele é o narrador de Contos gauchescos, de Simões Lopes Neto. Com uma sćrie de histórias, de "causos", 2 de descrições, Blau nos apresenta um universo. Seu relato recupcra um mundo perdido, o mundo gaúcho. Pela palavra, o passado revive, çuase com o mesmo colorido e emoçōes dos dias de glória. E a mocidade. o tempo do vigor que ainda vive na memória. E o mundo, não de um homem. ou de um gaúcho, mas aquele que existe implícito na alma de todo guasca de lei. Blau não fixa estc ou aquele tipo, fazendo de sua narrativa uma descrição de caracteres, mas, através do relato da açāo, leva o ouvinte, o "patrãozinho", e por extensāo o leitor, à apreensão total do mundo gaúcho. Mas ele sabe que esse é um mundo de vivências, um mundo para iniciados, que somente quando incorporado poderá ser dominado: "Vancê compre'nde, rião!" 3 o contador de histórias aparece ora como protagonista, ora como personagem secundário, ou ainda conhece as histórias como tradiçāo. Du-

- Trabalho apresentado à professora Cccllia Telxeira de Oliveira Zokner, para a disciplina Manifestaçōes Literárias na Região Sul: Literatura Gauchesca, do Curso de Especializaçāo em Literatura Brasileira, realizado no Setor de Ciências Humanas, Letras e Artes, em 1974. Grau obtido: oito. Parciaimente refeito.

* Marilene Weinhardt concluiu, em 1973, o curso de Letras e, stualmente, 6 Auxiliar de Ensino de Literatura Brasileira na Universidade Federal do Paraná. Publicou em Letras (n. 24) O Uso do diálogo no Memorial de Aires e em Arquivos (V. 2, n. 5 ) $O$ Narrador em Aquela casa triste.

1 TODOROV, Tzvetan. Os homens-narrativas. In: As estruturas narrativas. 2. ed. São Paulo Perspectiva, 1970. p. 119-33.

2 FILIPOUSKI, Ana Mariza et alii. Simōes Lopes Neto; a invenção, o mito e a mentira. Porto Alere, Movimento, 1973. p. 35.

3 SIMOES LOPES NETO, Joäo. Contos gauchescos. In: chescos e lendas do sul. 3. ed. Porto Alegre, Globo, 1965. p. 45. 
rante uma viagem, a memória trabalha casualmente: um encontro, a passagem por um lugar, um acontecimento que a propósito lembra outro.

Inicialmente, como uma garantia de crédito, apesar da apresentação que ihe é de todo favorávcl, Blau relata uma história que demonstra as suas qualidades que se confirmarāo depois: "Trezentas Onças".. O medo da desonra faz com que Blau pense no suicídio, preferivel a ser chamado de ladrāo. Mas, no momento fatal, o brilho das estrelas, o cachorro lambendo-lhe a mão e o cavalo relinchando lembra-lhe o respeito à vida que todo bom gaúcho tem. E, decidido, resolve voltar, vender tudo para pagar o perdido e recomeçar. Com isso, Blau está habilitado para nos apresentar o scu mundo. Ele jamais permite que nos esqueçamos do caráter de "história conta-

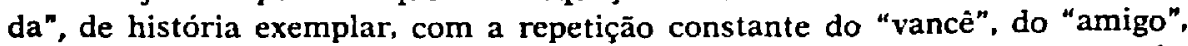
do "patrāozinho", do "escuite". E a chamada de atençāo, o presente que observa o passado. Esse elemento de "história contada" é auxiliado pelas reticências, que marcam o tempo de uma tragada, do mate, da respiração cansada. ou da coordenaçāo das idéias:

Parece que foi ontem!... Era por fevereiro; eu vinha abombado da troteada.

$[\ldots]$ até para quebrar a lombeira $[\ldots]$ e fui-me à água que nem capincho!

Por sinal que uma noite...

Mas isso é outra cousa; vamos ao caso. 4

E, pouco a pouco, sublinhado este ou aquele traço, configura-se-nos toda uma regiāo, um povo, suas tradiçōes. seu heroísmo, seus costumes.

$\mathrm{Da}$ primeira história. à qual já nos referimos, podemos tirar ainda outras conclusōes: o animal doméstico é um companheiro, entende o dono. Esse aspecto apresenta-se de modo bastante marcante quando o "cusco" de Blau parece chamá-lo para lembrar a guaiaca. Reaparccerá no "Boi Velho". Cabiúna berrava de saudades do companheiro morto e, ferido, dirigiu-se para a canga como se estivesse recebendo um castigo. Além destes exemplos. nos contos em que aparecem as "lides" campeiras, o cavalo é o "confiança" c o campeiro prefere matá-lo a vê-lo sofrer, como fez Juca Guerra. A perícia do cavalo e do cavaleiro formam um todo. numa estreita dependência. Mas a perícia do gaucho não se revela apenas no campo. Ele também é mestre nos trabahos com couro e na luta. Ai temos os exemplos de Mariano, de Juca Picumã, de Jango Jorge como contrabandista, e do próprio Blau. As falhas relatadas sempre sāo intencionais, dando oportunidade para que outra característica seja sublinhada. Mariano erra o tiro em Chicão, mas para dar outra feiçāo ao caso: atacá-lo com as próprias māos e ficarem três defuntos no manancial. O Binga_Cruz erra o laço na avestruz, corre muito, e por isso $c$ cavalo adocce e morre. Tandāo Lopes laça mal, dando lugar a outra função: Juca Guerra pode demonstrar sua perícia, coragem e companheirismo.

4 SIMOES LOPES NETO, p. 6. 
outras qualidades paralelas à hospitalidade e à lealdade na guerra. $\mathbf{E}$ respeito pelo ser humano. O gosto pela luta não se manifesta apenas na guerra, onde o gaucho muitas vezes nem sabe pelo que luta, mas também no entusiasmo de Blau ao relatar as brigas de botequim ou em festas, e o grande número de contos dedicados a este assunto. Brigas entre peōes ou luta contra os castelhanos sāo os motivos mais frequientes.

O gaucho $\mathfrak{i}$ sempre o herói, não de ocasião, mas por convicção. E o General Abreu, o Anjo da Vitória; o Juca Guerra, que Blau comenta não ser homem para morrer na cama, mas gloriosamente picado de espada na coxilha; o padrinho de Bleu; o Bento Gonçalves; o Costinha. Bento Gonçalves ilustra também a honra. na luta com o Coronel Onofre Pires. Essa qualidade do gaucho é reafirmada constantemente, sob os mais diversos aspectos. Para não ser acusado de ladrão. Blau quer suicidar-se; em outra ocasiāo declara ao imperador que sua divisa de cabo é sua familia; a velha que leva um fiambre ao imperador prefere não mais ver os filhos a vê-los derrotados; no conto "Os cabelos da china" Blau preocupa-se em saber se seu capitão não pretende matar o outro comandante amarrado; nesta mesma história Blau recusa-se a dizer que é desertor, e Juca Picumā repreende a filha pela sua conduta desavergonhada; em "Melancia - Coco Verde", Costinha vai para a luta no momento em que devia salvar a noiva; em "Jogo do osso" Chico Ruivo perde a china e entrega-a lealmente, mas quando ela beija o adversário. mata-os; Binga foge para não passar pela vergonha do guascaço de rabo-de-tatu. Os tipos negativos, como o negro Bonifácio e Chicāo, existem para dar oportunidade a uma ação corretiva. Sempre desaparecem e, ainda assim, existe neles certa honra, demonstrada por Chicão quando prefere ver Maria Altina morta a vê-la esposa de outro, e por Bonifácio na luta que provoca.

O herói não titubeia Suas decisōes sāo sempre rápidas. Mariano, o velho Lessa, Costinha, e o próprio Binga, nāo hesitam. A decisão junta-se a vivacidede, que tem o exemplo máximo no índio Reduzo, de "Melancia - Coco verde".

A liberdade é grande preocupação do gaucho. Isso explica o fanatismo pela República de Farrapos. Essa liberdade faz com que a família seja colocada em segundo plano. O verdadeiro guasca não se prende. Seu lugar é (: pago. Não existe a tradiçāo de família que se verifica na literatura nordestina. Uma ou outra vez cita-se a ascendência de uma personagem, não passando nunca de uma geração: o Nadico, filho do Antunes; os Costa, os Vieira; os Silva políticos. O papel da mulher é sempre secundário. Ela é um objeto, que o homem deve saber ter com honra, assim como à sua espada. No entanto, é de notar o papel da filha, que aparece em três histórias e pela qual o pai se sacrifica. Mariano morre pela filha, Juca Picumã mata seu capitāo para defender Rosa e o contrabandista Jango Jorge morre defendendo da guarda fronteiriça o vestido de noiva da filha. 
O gaucho acredita no sobrenatural e sua alma é impregnada de misticismo. Sua religiosidade tem sempre um quê de superstição: os fantasmas do manancial, o buçalete e o cabresto feitos dos cabelos de Rosa, o caixāo da mãc de Binga que não pesava nada porque ela nāo tinha pecado, a religiosidade do major Vieira que tinha sua origem num acontecimento da juventude (o Menino do presépio que caíra no seio da Nhã Velinda no momento em que o marido ia matá-la).

O gaucho é um forte, mas chora porque também é sentimental. Temos cinco referências ao choro, mas nunca por medo. Blau chora de emoção ao ver as Três Marias; lembrando de "correr eguada", Blau chora ao pensar no outro tempo, em criança. Blau chora quando morre o padrinho; Binga chora quando a avestruz foge; no enterro da mãe de Binga muitos choram.

Esse é o mundo que nos apresenta Simões Lopes Neto. Nāo é a grandeza de um personagem, mas através da reduplicaçāo de procedimentos semelhantes, configura-se um tipo humano em vias de desaperecer. Blau lembra com tristeza a fartura do passado. Várias histórias encaixadas na viagem constroem um modelo. E o modelo inconsciente, o arquétipo do gaucho. Em cada passagem de um estado de equilíbrio ao desequilibrio e o restabelecimento do equilíbrio, situação que permite a narrativa, uma faceta do inconsciente desse homem livre, heróico, orgulhoso de sua mentalidade. c apresentada. Contos gauchescos ć uma narrativa ideológica 5 que transforma o sistema de atitudes e de idéias da comunidade gauchesca $\mathrm{cm}$ fato literário. Blau é o intermediário desse mundo fechado, o porta-voz dessa realidade.

\section{REFERENCIAS BIBLIOGRAFICAS}

FILIPOUSKI. Ana Mariza et alii. Simōes Lopes Neto; a invençāo, o mito e a mentira. Porto Alegre, Movimento, 1973. $135 \mathrm{p}$.

SAN'T'ANNA, Affonso Romano de. Analise estrutural de romances brasileiros. Petrópolis, Vozes. 1973. $211 \mathrm{p}$.

SIMOES LOPES NETO, João. Contos gauchescos e lendas do sul. 3. ed. Porto Alegre, Globo, 1965. 175 p.

TODOROV, Tzvetan. As estruturas narrativas. 2. ed. Såo Paulo, Perspectiva, 1970. $204 \mathrm{p}$.

\section{Resumo}

A obra de Simōes Lopes Neto. Contos gauchescos, é a configuraçāo do universo gaúcho. Através da palavra, o narrador recupera um mundo em vias de desaperecer, colocando $\mathrm{cm}$ relevo todas as qualidades inerentes ao típico gaucho. E a transposição de uma mentalidade para a literatura.

5 SANT'ANNA, Affonso Romano de. Elementos para uma teoria do romance (no Brasil). In:

Análise estrutural de romances brasileiros. Petrópolis, Vozes, 1973. p. 32-53. 


\section{Résumé}

L'oeuvre de Simões Lopes Neto, Contos gauchescos, configure l'univers des habitants de la région "dos pampas". La parole du narrateur recouvre t:n monde en train de disparaitrc. La narration met en relief toutes les qualités propres au "gaucho". C'est la transformation de la mentalité et de l'esprit d'un peuple en littérature. 